\title{
A STUDY ON PERIPHERAL NEUROPATHY AND ITS RELATED RISK FACTORS ASSOCIATED WITH HbA1C LEVELS
}

\author{
MA Hossain ${ }^{1}$, MK Sarkar ${ }^{2}$ I Mahbub ${ }^{3}$ and SMS Islam ${ }^{1^{*}}$ \\ 1 Plant Biotechnology and Genetic Engineering Lab., Institute of Biological Sciences, University of Rajshahi, \\ Rajshahi-6205, Bangladesh \\ 2Department of Neurology, Rajshahi Medical College, Rajshahi, Bangladesh \\ ${ }^{3}$ Department of Endocrinology, Sheikh Hashina National Institute of Burn and Plastic Surgery, Dhaka, \\ Bangladesh
}

\begin{abstract}
Diabetic peripheral neuropathy (DPN) patients frequently feel persistent pain, which is described as painful diabetic peripheral neuropathy (PDPN), which begins in both feet and frequently spreads to the calves, fingers, and hands. PDPN not only causes pain, but also affects patients' sleep, emotions, mental state, and everyday activities, resulting in a low quality of life and a significant financial burden. The goal of this study was to monitor if there was a link between the prevalence, pattern, and related risk factors of diabetic peripheral neuropathy and hemoglobin $\mathrm{A} 1 \mathrm{C}$ (HbA1c) levels. In this crosssectional study, 150 type-2 diabetic patients were screened for DPN with PDPN and their HbA1c level was measured in every three months. DPN, PDPN and non-painful DPN were confirmed in patients displaying both clinical manifestations of neuropathy and neurological abnormalities assessment. DPN was detected in $24 \%(n=36)$, while PDPN was found at $15 \%(n=23)$ of the total patients. The prevalence of PDPN is $63.88 \%(n=23)$ and non-painful DPN is $36.11 \%(n=13)$ of total DPN $(n=36)$. Out of total PDPN ( $n=23)$, the prevalence of symmetrical pain is $65 \%(n=15)$, asymmetrical $35 \%(n=$ 8), sensory 26\% ( $n=6)$, motor $13 \%(n=3)$, mixed (sensorimotor) $61 \%(n=14)$, lower limb involvement 48\% ( $n=11)$, upper $\operatorname{limb13\% }(n=3)$ and both $\operatorname{limb} 39 \%(n=9)$. In comparison to patients without DPN, both PDPN and non-painful DPN, patients had greater HbA1c levels $(p<0.05)$. Furthermore, advanced age and longer diabetes duration were considerable and significant $(p<0.05)$ risk factors for DPN with PDPN and non-painful DPN respectively. Overall, the findings imply that elevated $\mathrm{HbA1c}$ levels are closely linked to DPN, PDPN and non-painful DPN in type-2 diabetic patients and that HbA1c might be used as a predictive marker for DPN with PDPN and non-painful DPN in the patients studied.
\end{abstract}

Key words: Diabetic peripheral neuropathy, Painful diabetic peripheral neuropathy, Type-2 diabetes, HbA1c

\section{Introduction}

Diabetes mellitus (DM) is a kind of hyperglycemia that is linked to metabolic syndrome, a condition marked by insulin resistance (Gallagher et al. 2011). Diabetes mellitus has reached epidemic proportions worldwide, with 700 million people expected to have the disease by 2045 (IDF Atlas 2019). Two-thirds of diabetics live in cities, and three out of every four are working age. Diabetes-related deaths are expected to kill almost four million persons aged 20 to 79 in 2019. In Bangladesh, 8.4 million people have diabetes and 4.7 million are undiagnosed (IDF Atlas 2019). Long-term diabetes damages several organs, resulting in serious retinopathy, nephropathy, and neuropathy problems (Gionfriddo et al. 2014). Increased HbA1c concentration is the most

*Author for correspondence: shahinul68@gmail.com 
important risk factor for predicting DM problems (Hossain et al. 2021). HbA1c is plasma glycosylated hemoglobin $(\mathrm{HbA} 1 \mathrm{c})$ that serves as an indication of average glycemic control over the past 2-3 months and signals poor diabetic management. Maintaining an $\mathrm{HbA1c}$ level of less than $6.5 \%$ is essential for reducing the risk of diabetic complications (International Expert Committee 2009). Diabetic peripheral polyneuropathy, which involves peripheral nerve injury, is one of the most prevalent consequences of diabetes, affecting about $8 \%$ of newly diagnosed individuals and more than 50\% of long-term DM patients (Deli et al. 2013). Painful diabetic neuropathy (PDN), as well as bothersome autonomic characteristics such as orthostatic hypotension, are clinical symptoms of DPN (Boulton et al. 2005), autonomic neuropathy of the heart (a clinical condition which can result in sudden death) (Vinik and Ziegler 2007), noncardiac autonomic neuropathy causes a variety of different diseases (such as gastro-paresis and erectile dysfunction) (Vinik and Ziegler 2007), and a lack of trauma sensitivity (which can result in ulceration, infections, and lower extremity amputations) (Boulton et al. 2005, Narres et al. 2017).

Diabetic neuropathies are one of the most common long-term effects of diabetes (Dyck et al. 1993, Hossain et al. 2021). Polyneuropathy symptoms range from severe sensory alterations to motor weakness. Painful diabetic neuropathy (PDN) is a prevalent diabetic condition that affects up to one-third of people globally. Because of the diversity of pathophysiological pathways leading to pain, diagnosing, treating, and managing PDN can be difficult for doctors (Bril et al. 2011, Aslam et al. 2014). According to length dependency, the most common symptoms are symmetrical paresthesia and searing sensation in the legs. Foot ulceration and nontraumatic amputation are two severe consequences that can occur (Feng et al. 2011).

The most prevalent form of DPN is chronic sensorimotor distal symmetric polyneuropathy (Boulton et al. 2005), which causes significant sensory loss, muscle weakness, and discomfort. The most common symptom of DPN is a gradual onset of sensory abnormalities in the feet, such as burning and numbness. Indeed, the disease's onset is so slow that it may go untreated for years. Although neuropathic pain can be severe when it occurs, it is only found to occur in $11 \%$ to $32 \%$ of people with DPN (Vinik et al. 2000). Damage to the dysfunction of the system that conveys pain causes PDPN (National Institute for Health and Care Excellence 2013, Alleman et al. 2015). PDPN patients describe their symptoms as burning, aching, shooting, and stabbing, with nocturnal exacerbations common (Tesfaye 2009, Tesfaye and Selvarajah 2009). PDPN can be found in the arms, hands, legs, and feet (Jensen et al. 2007). DPN (distal symmetrical polyneuropathy) is the most common kind of diabetic neuropathy, affecting up to $50 \%$ of patients (Dyck et al. 1993, Tesfaye et al. 2005, Pop-Busui et al. 2017, Hossain et al. 2021). According to a more recent definition of DPN in the American Diabetes Association Position Statement, "the existence of symptoms and/or evidence of peripheral nerve damage in patients with diabetes after the exclusion of alternative causes" (Pop-Busui et al. 2017). The increased number of patients identified with DM-related neuropathic illnesses will have a significant influence on health and social care services (Sadosky et al. 2015). The intensity of the neuropathic pain is variable (Taylor-Stokes et al. 2011). Different clinical symptoms exist in DPN and painful DPN, the most prevalent of which is a mixed large and small fiber neuropathy. Small nerve fibers (SF) are sensory fibers with a small caliber that are responsible for peripheral nociception (Lauria et al. 2012). Regardless of whether or not pain is present, patients may experience numbness, tingling, or pins and needles. Neuropathic pain, especially moderate to severe neuropathic pain, can cause physical impairment, sadness, anxiety, sleeplessness, and a lower quality of life than people with painless-DPN (Gore et al. 2005, Themistocleous et al. 2016, Raputova et al. 2017, ADA 2020, Jensen et al. 2007, O'Connor 2009). Despite 
the significant changes in a patient's clinical presentation, the neurological examination of painless and painful-DPN patients are is very similar. On clinical examination, the majority of patients with painful-DPN exhibit sensory loss, while a small percentage of patients with painful-DPN have indicators of "gain of function," such as allodynia and hyperalgesia (Themistocleous et al. 2016). In general, pain relief (as a result of treatment) is linked to an increase in quality of life (Deshpande et al 2006, Attal et al 2010). When compared to diabetic patients without DPN of the same age and sex, painful DPN is said to result in significantly higher healthcare costs. Even after accounting for differences in concomitant medical conditions such as cardiovascular disease, annual healthcare costs in two independent databases were $24 \%-38 \%$ higher (Dworkin et al. 2010). According to the IDF, overall diabetes health costs were USD 760.3 billion in 2019, and are expected to rise to USD 845.0 billion by 2045. According to one analysis, global GDP losses from 2011 to 2030, including both direct and indirect diabetes costs, will exceed US\$ 1.7 trillion, with 900 billion in high-income nations and 800 billion in low- and middle-income countries (Bloom et al. 2012). The exact processes that cause diabetic polyneuropathy are unknown; however, they appear to include systems that are only indirectly related to hyperglycemia (Toth et al. 2008, Obrosova 2009, King and Evcimen 2010). Currently, there is no specific treatment for DPN other than glycemic control which modestly slows the progression of nerve damage but cannot reverse the process (ADA 2021). Many researchers have looked into the link between $\mathrm{HbA1c}$ levels and DM complications. A study in Bangladesh reported the prevalence of DPN is 19.7\% (Mørkrid et al. 2010). However, little study has been done on the HbA1c level that is crucial in different characteristics of PDPN or non-painful DPN. The aim of this study was to estimate the prevalence of DPN and to identify its risk factors in type 2 diabetic patients, with a view to provide necessary data to identify differential risk factors, which may ensure improved preventive measures and care for diabetic patients.

\section{Material and Methods}

This descriptive cross-sectional comparative study has been carried out from July 2017 to June 2018 in the outpatient department of Rajshahi Diabetic Association General Hospital, Rajshahi, Bangladesh. Total 150 diabetic type-2 patients were included randomly with or without DPN with inclusion (age $>25$, both male and female, patients who fulfilled the WHO criteria of type-2 diabetes mellitus) and exclusion criteria (other known causes of peripheral neuropathy, taking any drug causes peripheral neuropathy, other cusses of pain rather than DPN and also other types of diabetics rather than DM-2). Data was collected by a prescribed data collection sheet with the written consent of all individual patients through a personal interview, anthropometric measurement, investigations, examinations and previous history from the patient's diabetic record book. The HbA1c level was determined using ionic exchange HPLC (IE-HPLC) in the D-10 hemoglobin analysis system (Bio-Rad). In terms of a clinical diagnosis, it is generally agreed that DPN can be diagnosed by the presence of a combination of peripheral symptoms and neurological deficits (Boulton et al. 1998, Hossain et al. 2021). DPN was diagnosed in patients displaying both the presence of neurological symptoms and neuropathic symptoms including numbness, tingling, prickling, or burning pain in the legs and/or feet or upper limbs, symmetrical or asymmetrical. Neuropathic signs were defined as reduced or absent ankle jerk reflexes, knee jerk reflexes, biceps reflex, triceps reflex and supinator jerk reflexes (using an appropriate reflex hammer) and reduced or absent distal sensation, including vibration perception (using a 128-Hz tuning fork), touch sensation (using a $10 \mathrm{~g}$ monofilament), thermal discrimination (using cold and warm objects), pinprick sensation (using a pin) and proprioception. Signs were evaluated through careful neurological examinations. 
At least one sensory function was impaired in the participant, including vibration sensation, monofilament sensation, touch sensation, pain sensation, thermal sensation, and position sensation, confirming DPN but at least two common symptoms of PDPN, such as burning sensation, numbing sensation, electric shocks, tingling pain, sharp or stabbing pain, or pins and needles. All of the data were articulated as mean \pm SD (standard deviation) of the mean. Data have been analyzed using IBM SPSS software (version 20) and compared by Student t-test and $p$-value $<0.05$ was considered as statistically significant.

\section{Results}

The clinical parameters of all participants are summarized in Table 1. A total of 150 type-2 diabetic patients were recruited randomly, where 36 (24\%) had been confirmed with DPN. Among the 150 patients, 81 were female and 69 were male patients. The patients with DPN presented significantly $(p<0.05)$ higher age 53.22 \pm 6.99 (mean $\pm \mathrm{SD}$ ) years, higher duration of diabetes $8.19 \pm 5.11$ (mean $\pm \mathrm{SD}$ ) years and higher HbA1C level $10.38 \pm 2.12$ (mean \pm SD) than non-DPN patient's mean age $45.97 \pm 9.86$ (mean \pm SD) years, duration of diabetes $3.77 \pm 3.92$ (mean $\pm \mathrm{SD}$ ) years and $\mathrm{HbA1c}$ level $8.88 \pm 1.96$ (mean $\pm \mathrm{SD}$ ) respectively. In our study, no significant $(p>0.05)$ difference was found in the case of BMI level, systolic and diastolic BP between DPN and non-DPN participants.

Table 1. Clinical characteristics of the participants of DPN

\begin{tabular}{lcccc}
\hline Variables & \multicolumn{3}{c}{ Type 2 diabetic patients } & \multirow{2}{*}{$P$-value } \\
\cline { 2 - 4 } & Total & Non-DPN & DPN & \\
\hline $\mathrm{n}$ & 150 & $114(76 \%)$ & $36(24 \%)$ & - \\
Male & $69(46 \%)$ & $47(68.1 \%)$ & $22(31.9 \%)$ & - \\
Female & $81(54 \%)$ & $67(72.7 \%)$ & $14(17.28 \%)$ & - \\
Age (year) & $48.58 \pm 9.56$ & $45.97 \pm 9.86$ & $53.22 \pm 6.99$ & 0.000046 \\
BMl & $24.35 \pm 3.99$ & $23.91 \pm 3.49$ & $25.14 \pm 4.69$ & 0.174743 \\
Systolic BP & $123.7 \pm 14.64$ & $121.88 \pm 13.61$ & $126.94 \pm 16.00$ & 0.114088 \\
Diastolic BP & $75.57 \pm 13.26$ & $75.34 \pm 15.10$ & $75.97 \pm 9.32$ & 0.797649 \\
Duration (year) & $5.27 \pm 4.77$ & $3.77 \pm 3.92$ & $8.19 \pm 5.11$ & 0.00003 \\
HbA1c (\%) & $9.42 \pm 2.13$ & $8.88 \pm 1.96$ & $10.38 \pm 2.12$ & 0.000848 \\
\hline
\end{tabular}

Table 2 shows the distributions of different characteristics (PDPN, non-painful DPN, symmetrical, nonsymmetrical, lower limb, upper limb and both limb involvement, sensory, motor and mixed type of pain) of 36 DPN patients (22 males and 14 females). Out of 22 male DPN patients, 11 patients are PDPN and the remaining 11 are non-painful DPN. On the other hand, 12 female patients are PDPN out of 14 DPN while only 2 patients are non-painful DPN. Out of total PDPN (23 patients), symmetrical (15 patients), asymmetrical (8 patients), lower limb, upper limb and both limbs are 11, 3 and 9 respectively. On the other hand sensory, motor and mixed types of pain are 6, 3 and 14 respectively. 
Peripheral Neuropathy and its Related Risk Factors with $\mathrm{HbA1c}$

Table 2. Different Painful neuropathic signs and/or symptoms of patients with DPN

\begin{tabular}{|c|c|c|c|c|c|c|c|c|c|c|c|}
\hline \multirow{2}{*}{\multicolumn{2}{|c|}{$\begin{array}{c}\text { Type and } \\
\text { number of } \\
\text { patients }\end{array}$}} & \multicolumn{2}{|c|}{ Presence of pain } & \multicolumn{2}{|c|}{ Pain pattern } & \multicolumn{3}{|c|}{ Involvement of pain } & \multicolumn{3}{|c|}{ Pain character } \\
\hline & & \multirow{2}{*}{$\begin{array}{c}\text { Painful } \\
\text { No }\end{array}$} & \multirow{2}{*}{$\begin{array}{c}\begin{array}{c}\text { Non- } \\
\text { painful }\end{array} \\
\text { Yes }\end{array}$} & \multirow{2}{*}{$\begin{array}{c}\text { Symmetrical } \\
\text { No }\end{array}$} & \multirow{2}{*}{$\begin{array}{c}\text { Asymmetrical } \\
\text { No }\end{array}$} & \multirow{2}{*}{$\begin{array}{c}\begin{array}{c}\text { Lower } \\
\text { Limb }\end{array} \\
\text { No }\end{array}$} & \multirow{2}{*}{$\begin{array}{l}\begin{array}{l}\text { Upper } \\
\text { Limb }\end{array} \\
\text { No }\end{array}$} & \multirow{2}{*}{$\begin{array}{c}\text { Both } \\
\text { No }\end{array}$} & \multirow{2}{*}{$\begin{array}{c}\text { Sensory } \\
\text { No }\end{array}$} & \multirow{2}{*}{$\begin{array}{l}\text { Motor } \\
\text { No }\end{array}$} & \multirow{2}{*}{$\begin{array}{c}\text { Mixed } \\
\text { No }\end{array}$} \\
\hline \multirow{22}{*}{$\begin{array}{l}\frac{\sum}{\frac{\omega}{\pi}} \\
\frac{\pi}{2}\end{array}$} & 1 & & & & & & & & & & \\
\hline & 2 & Yes & No & No & Yes & No & No & Yes & No & No & Yes \\
\hline & 3 & Yes & No & Yes & No & Yes & No & Yes & Yes & No & No \\
\hline & 4 & No & Yes & No & No & No & No & No & No & No & No \\
\hline & 5 & Yes & No & No & Yes & No & Yes & No & No & No & Yes \\
\hline & 6 & No & Yes & No & No & No & No & No & No & No & No \\
\hline & 7 & No & Yes & No & No & No & No & No & No & No & No \\
\hline & 8 & No & Yes & No & No & No & No & No & No & No & No \\
\hline & 9 & No & Yes & No & No & No & No & No & No & No & No \\
\hline & 10 & Yes & No & Yes & No & No & No & No & Yes & No & No \\
\hline & 11 & Yes & No & Yes & No & Yes & No & No & No & Yes & No \\
\hline & 12 & No & Yes & No & No & No & No & No & No & No & No \\
\hline & 13 & Yes & No & No & Yes & Yes & No & No & No & No & Yes \\
\hline & 14 & No & Yes & No & No & No & No & No & No & No & No \\
\hline & 15 & Yes & No & Yes & No & No & No & Yes & Yes & No & No \\
\hline & 16 & No & Yes & No & No & No & No & No & No & No & No \\
\hline & 17 & Yes & No & No & Yes & Yes & No & No & No & No & Yes \\
\hline & 18 & No & Yes & No & No & No & No & No & No & No & No \\
\hline & 19 & Yes & No & Yes & No & No & Yes & No & No & No & Yes \\
\hline & 20 & No & Yes & No & No & No & No & No & No & No & No \\
\hline & 21 & Yes & No & Yes & No & No & No & Yes & No & No & Yes \\
\hline & 22 & Yes & No & Yes & No & Yes & No & No & No & No & Yes \\
\hline $\begin{array}{c}\text { Sub-total } \\
\text { (M) }\end{array}$ & 22 & 11 & 11 & 7 & 4 & 5 & 2 & 4 & 3 & 1 & 7 \\
\hline \multirow{14}{*}{ 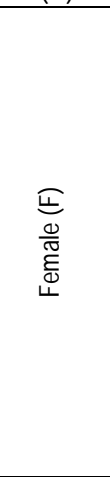 } & 1 & Yes & No & No & Yes & No & Yes & No & Yes & No & No \\
\hline & 2 & No & Yes & No & No & No & No & No & No & No & No \\
\hline & 3 & Yes & No & Yes & No & Yes & No & No & No & No & Yes \\
\hline & 4 & No & Yes & No & No & No & No & No & No & No & No \\
\hline & 5 & Yes & No & Yes & No & Yes & No & No & No & Yes & No \\
\hline & 6 & Yes & No & Yes & No & Yes & No & No & Yes & No & No \\
\hline & 7 & Yes & No & Yes & No & No & No & Yes & No & No & Yes \\
\hline & 8 & Yes & No & No & Yes & No & No & Yes & No & No & Yes \\
\hline & 9 & Yes & No & Yes & No & Yes & No & No & No & No & Yes \\
\hline & 10 & Yes & No & No & Yes & No & No & Yes & Yes & No & No \\
\hline & 11 & Yes & No & Yes & No & Yes & No & No & No & Yes & No \\
\hline & 12 & Yes & No & No & Yes & No & No & Yes & No & No & Yes \\
\hline & 13 & Yes & No & Yes & No & No & No & Yes & No & No & Yes \\
\hline & 14 & Yes & No & Yes & No & Yes & No & No & No & No & Yes \\
\hline $\begin{array}{c}\text { Sub- } \\
\text { Total (F) }\end{array}$ & 14 & 12 & 2 & 8 & 4 & 6 & 1 & 5 & 3 & 2 & 7 \\
\hline $\begin{array}{c}\text { Grand } \\
\text { Total } \\
\text { (M \& F) }\end{array}$ & 36 & 23 & 13 & 15 & 8 & 11 & 3 & 9 & 6 & 3 & 14 \\
\hline
\end{tabular}

Fig. 1 shows prevalence of PDPN is $15 \%(n=23)$ which is higher than non-painful DPN prevalence which is $9 \%(n=11)$ whereas DPN prevalence is $24 \%(n=36)$ patients. 


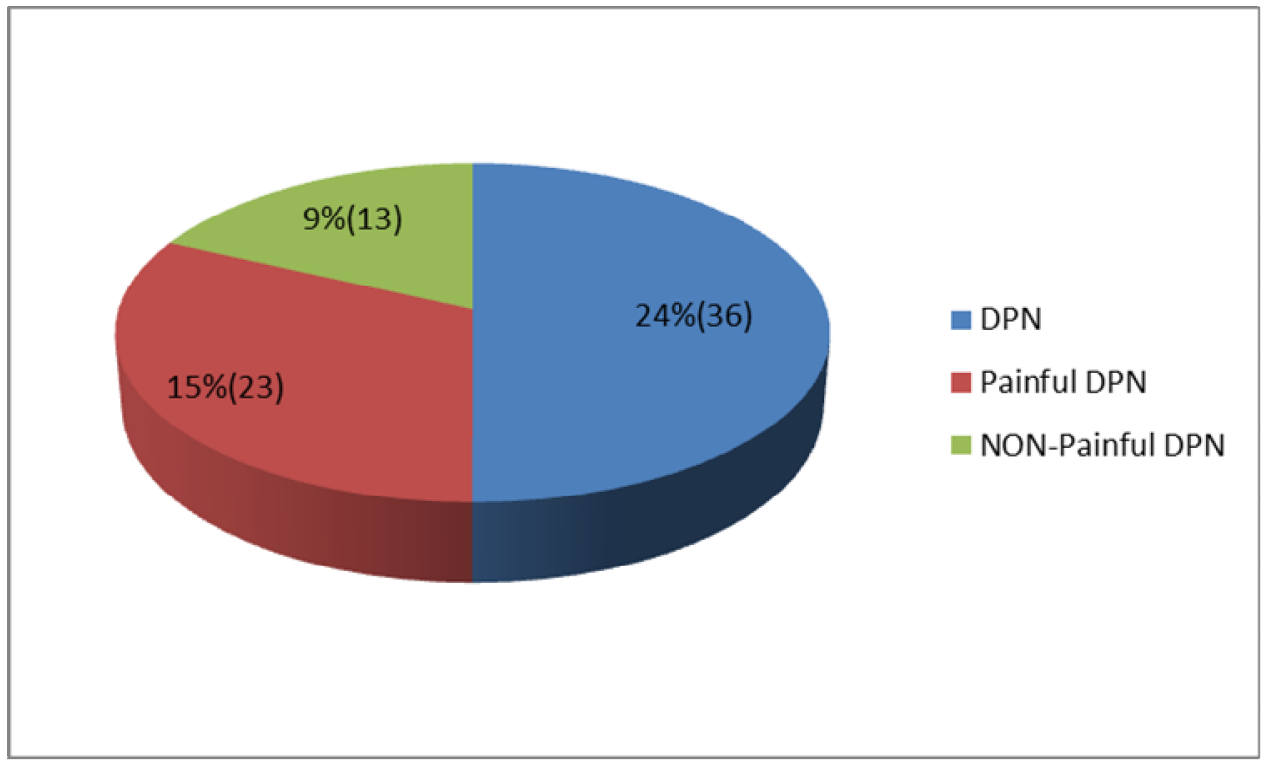

Fig. 1: Prevalence of PDPN, DPN and Non-painful DPN among (150 patients).

Fig. 2 mentioned the prevalence of PDPN and non-painful DPN which are $63.88 \%$ and $36.11 \%$ respectively among total DPN. Here total DPN indicate $100 \%(n=36)$.

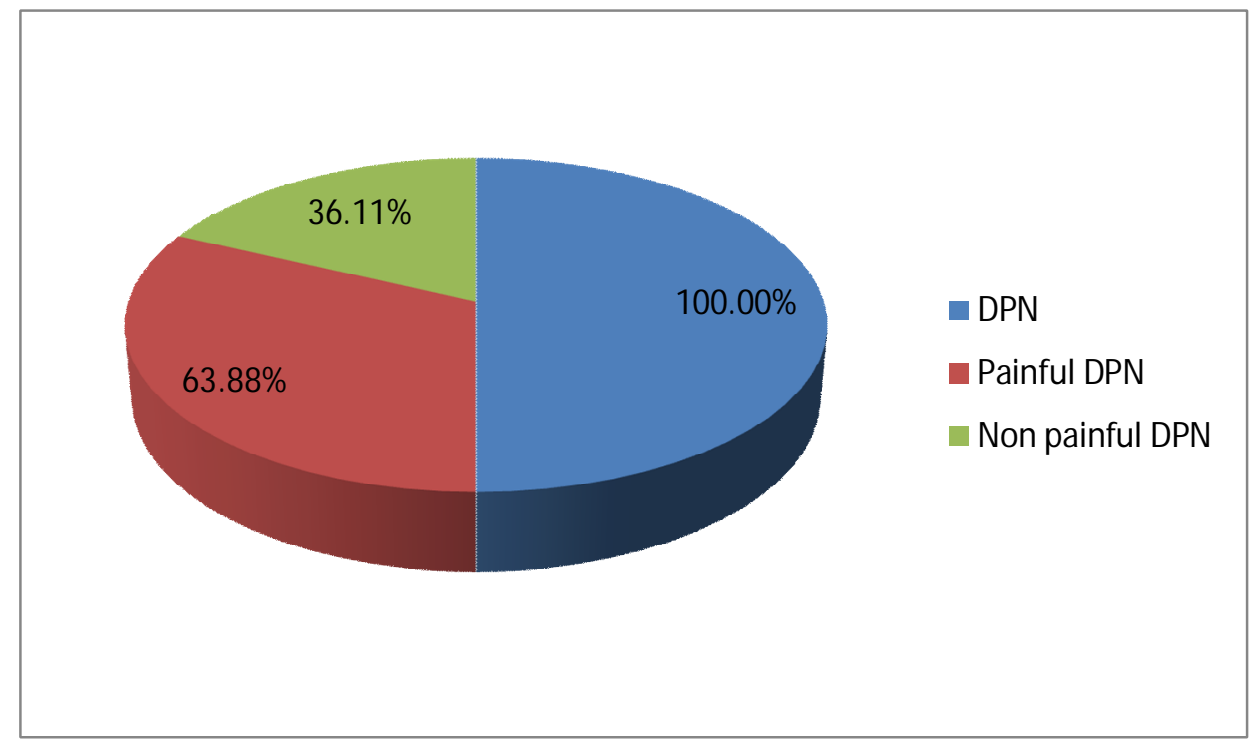

Fig. 2: Prevalence of PDPN, Non-painful DPN among total DPN (36 patients). 
Fig. 3 shows the most frequent neurological symptom for 7 males and 8 females was symmetrical involvement of PDPN in limbs whereas the least frequent symptom was found for both upper limb ( 2 males \& 1 female) and motor ( 1 male \& 2 females) involvement. The second most frequent symptom (7 males \& 7 females) was mixed (sensorimotor). The third frequent symptom was in lower limb (5 males \& 6 females) involvement. Both limbs ( 4 males \& 5 females) involvement were in the fourth position. The fitth and the sixth positions were asymmetrical ( 4 males \& 4 females) and sensory ( 3 males \& 3 females) respectively. These all the frequencies mentioned above, among 23 patients out of total 36 DPN patients who were painful where 11 male and 12 female patients. Females were more sufferers both in the number and frequencies of PDPN.

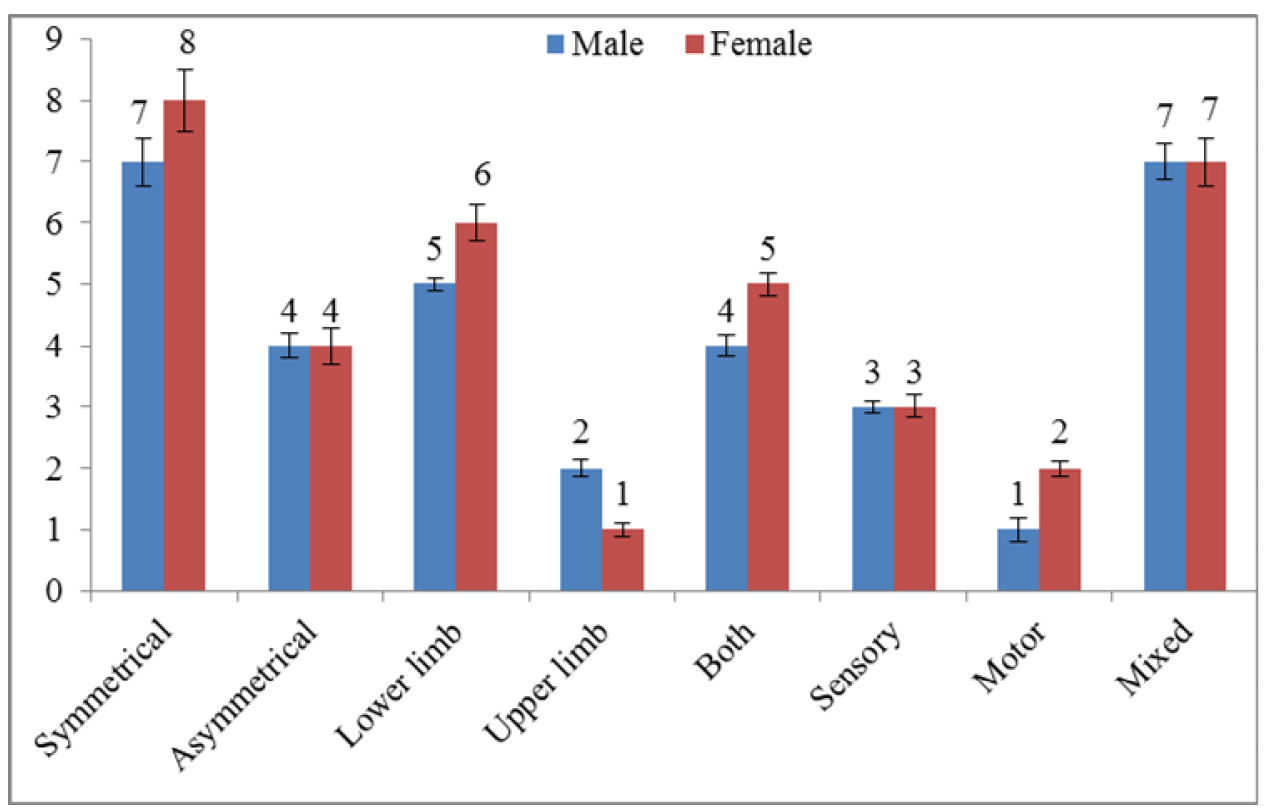

Fig. 3: Frequency of Painful neuropathic signs and/or symptoms of patients with DPN.

Fig. 4 shows the prevalence distribution of different characters, patterns and involvement of pain. The result shows the highest prevalence is $65 \%$ that is a symmetrical pattern but the lowest prevalence is $13 \%$ both in the case of the upper limb and motor respectively. The second highest prevalence is mixed (sensory motor) type of pain which is $61 \%$. The prevalence of lower limb involvement was $48 \%$ which was in the third position. The prevalence of both limbs was 39\% and is in the fourth position. $35 \%$ and $26 \%$ are the prevalence of asymmetrical and sensory respectively and fifth and sixth position also. 


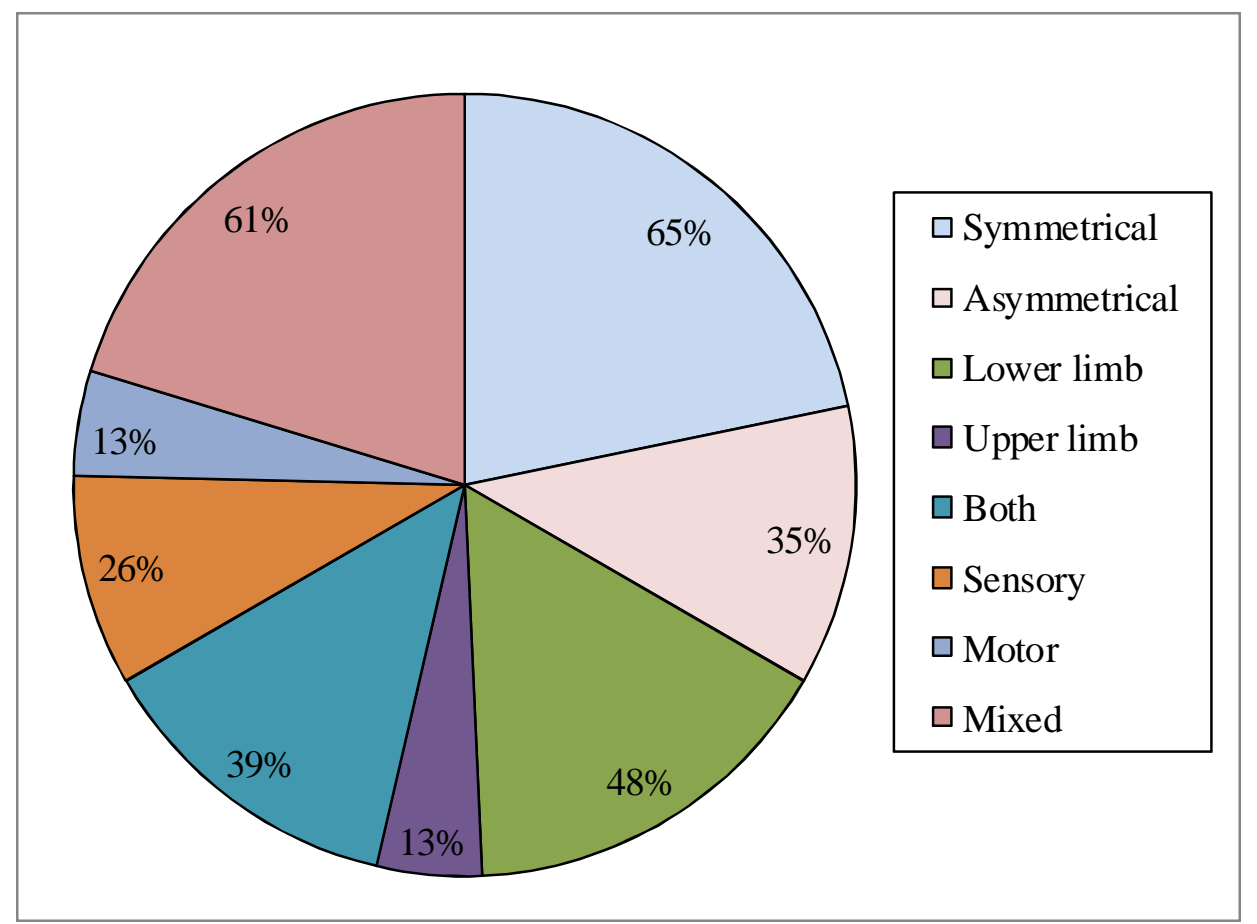

Fig. 4: Prevalence distribution of Painful neuropathic symptoms (among total PDPN) of patients with DPN.

\section{Discussion}

In the present study, we investigated the association of $\mathrm{HbA1c}$ with the prevalence of different characteristics of DPN in type-2 diabetic patients. The strength of the study is that the increased HbA1c variability was shown to be a significant and independent contributor to DPN with or without pain. In this study, the mean age of the DPN participants was $53.22 \pm 6.99$ years and the mean duration of diabetes was $8.19 \pm 5.11$ years. A study in Bangladesh reported by Mørkrid et al (2010) that the prevalence of DPN in type 2 diabetic patients was 19.7\% (mean age in the DPN-group: $55.1 \pm 10.5$ years, mean duration of diabetes: $7.7 \pm 1.9$ years) (Mørkrid et al. 2010). Whereas the average age of the DPN patients in this study was $53.22 \pm 6.99$ years, with average diabetes duration of $8.19 \pm 5.11$ years. This finding suggests that in Bangladesh, the average age for having diabetes is getting younger. A study from an Indian diabetes facility identified a DPN prevalence rate was $19.1 \%$ among type 2 diabetic outpatients, which was similar to the current study's prevalence rate (24\%) (Mean age in the DPN-group: $62 \pm 8$ years, mean duration of diabetes: $12 \pm 8$ years) (Ashok et al. 2002). In comparison to the results from India, diabetic complications in Bangladeshi individuals appeared earlier, both in terms of patient age and diabetes duration. In comparison to European research, Bangladesh has a lower prevalence rate of DPN (Cabezas-Cerrato 1998, BÖRü et al. 2004) with an overall prevalence rate of $32.1 \%$ (mean age: 63 years, mean duration of diabetes: six years) (Young et al.1993); $35.4 \%$ (mean age: 61.3 years, mean duration of diabetes: 9.7 years) (Cabezas-Cerrato 1998) and $60.0 \%$ (mean age: $57.2 \pm 10.3$, mean duration of diabetes: $8.52 \pm 7.13$ years) (BÖRü et al.2004) among diabetic hospital outpatients with type 2 diabetes. Even after correcting for age, studies in the UK found a lower DPN prevalence (11.9\%) among type 2 diabetic South-Asian patients compared to European patients living in the 
UK (Chaturvedi et al. 2002, Abbott et al. 2005). However, this discrepancy could be because the diagnostic criteria utilized in those western studies differ from those used in the current investigation, as stated by Morkid and colleagues (Mørkrid et al. 2010). Our respondents' average age was $48.58 \pm 9.56$ years, suggesting that the diabetes population in this region of the world is younger than in the West (Hossain et al. 2005, Mørkrid et al. 2010).

In this study, it was found that advanced age and diabetes over a longer period were important risk factors for peripheral neuropathy. These findings were consistent with those of other investigations (Mørkrid et al. 2010, Suljic et al. 2013, Darivemula et al. 2019, Punjot et al. 2021). HbA1c, fasting blood glucose levels, and two hours after breakfast were found to be key risk factors for peripheral neuropathy. These findings were in line with other reports (Chang et al. 2012, Kumar et al. 2012, Agrawal et al. 2014). There was no evidence of a link between systolic and diastolic blood pressure and peripheral neuropathy (Ramchandran et al. 1999) likewise found no substantial link between hypertension and diabetic neuropathy, however, some disagreed with this present study (Knuiman et al. 1986, Agrawal et al. 2014). However, we discovered that systolic and diastolic blood pressures had no significant relationship with peripheral neuropathy in our study.

HbA1c may exhibit a glycaemic threshold with micro and macrovascular consequences of diabetes, according to several studies, suggesting it could be a valuable biomarker to identify those at risk for various vascular issues (Zoungas et al. 2012, Gorst et al. 2015). In this study, it was observed that increasing HbA1c categories above almost $9.0 \%$ were significantly associated with increased prevalence of DPN. Results of this study were consistent with those who reported that increasing HbAlc categories $(\geq 8 \%)$ had a higher prevalence of peripheral neuropathy (21.2\%) (Sabanayagam et al. 2009). Another study also found a similar association of HbA1c with neuropathy (Gorst et al. 2015). The apparent HbA1c level threshold for microvascular events was found to be $6.5 \%$ (Zoungas et al. 2012). They also showed that, over certain thresholds, a greater HbA1c level was linked to a higher risk of microvascular events in a log-linear fashion. There was no significant link between mean $\mathrm{HbA1c}$ levels and risks below these levels. At HbA1c levels less than $7.0 \%$, there were relatively few DPN episodes seen in the current study.

$\mathrm{HbA1c}$ variability, which measures long-term glycemic fluctuation, may induce oxidative stress (Chang et al. 2012), the Enhanced activity of the hexosamine pathway, as well as augmented flux through the polyol pathway, overproduction of precursors of advanced glycation end products, overactivation of protein kinase $\mathrm{C}$ isoforms, and overactivation of protein kinase $\mathrm{C}$ isoforms, may all contribute to tissue and cell damage. Furthermore, HbA1c fluctuation may boost the expression of a systemic inflammatory marker which is linked to vascular damage (Brownlee 2005). Another way that $\mathrm{HbA1C}$ fluctuation plays a role in diabetic complications is through cellular metabolic memory, which differs from short-term glycemic variability (Brownlee 2005). Excessive cellular indicators of DNA damage and hyperactivation of tumor suppressor transcription factors are produced by prolonged exposure to glycemic fluctuation, which may lead to a stronger metabolic memory effect than chronic hyperglycemia (Schisano et al. 2011). These cell damages can affect neurons as well as supporting tissue such as neuroglial cells and capillaries, resulting in nerve dysfunction and neuropathy (Callaghan et al. 2012). Therefore, HbA1c variability may be a potential factor associated with DPN risk.

In the current study, type-2 diabetes patients had a 15\% of PDPN and a $24 \%$ prevalence of DPN. The prevalence of PDPN is $63.88 \%$ among DPN. The prevalence of PDPN in this study was consistent with the prevalence of $14 \%$ Turkey (Erbas et al. 2011), and 12\% - 18\% in Hong Kong, Taiwan, and Thailand, according to physicians (Davies et al. 2006, Sadosky et al. 2008, Veves et al. 2008, Alleman et al. 2015). While physicians in Malaysia and the Philippines estimated PDPN prevalence at $29 \%$ and $33 \%$, respectively, similar to that reported in Western countries (Veves et al. 2008, Alleman et al. 2015), which is higher than the 
current study. In a nationwide, hospital-based, observational study of type 2 diabetes in Korea, the estimated PDPN prevalence was $14.4 \%$, which is consistent with our study. However, the prevalence of PDPN among DPN of our study is greater than 43.1\% (PDPN) of DPN patients in Korea (Kim et al. 2014). In Japan, 22.1\% of diabetic outpatients were found to have PDPN (Tsuji et al. 2013), and it is estimated that $15 \%-25 \%$ of DPN cases are associated with neuropathic pain (Harris et al. 1993, Boulton et al. 2004, Davies et al. 2006, Sadosky et al. 2008), all of which support the findings of this study. Although there were fewer females with clinical neuropathy than males, more females than males reported painful neuropathy symptoms (Abbott et al. 2011) which are consistent with our study where the prevalence of DPN is higher in males (31.9\%) compared to females (17.28\%) in contrast with PDPN. In our study, old age, longer duration of diabetes and higher HbA1c level are significantly higher in DPN which is consistent with other studies (Darivemula et al. 2019, Punjot et al. 2021). Tesfaye et al. (2005) and Punjot et al. (2021) shown HbA1c and diabetes duration have been identified as risk factors for diabetic peripheral neuropathy (Tesfaye et al. 2005, Punjot et al. 2021). In a study, age and HbA1C levels were found to be independent risk factors for polyneuropathy comorbidity in diabetic patients (Lee et al. 2016, Punjot et al. 2021). According to the study by Zigmond and Snaith (1983), there was no difference in the clinical variables between patients with and without DPN. There was no significant difference in age, sex, diabetes duration, BMI, or glycemic control between patients with and without PDN (Zigmond and Snaith 1983). Therefore, age, sex, duration of diabetes, body mass index and glycemic control are the same as DPN with or without pain because DPN comprises PDPN and nonPDPN which is in favor of our studies. In another study, PDN affects a high number of Japanese diabetic patients (22.1\%) (Tsuji et al. 2013). Davies et al. (2006) found a prevalence of PDN of 26\% in the United Kingdom (Davies et al. 2006). In a research by Van Acker et al. (2009) in Belgium, 14\% of the patients had lower limb neuropathic pain. In another report, $42.2 \%$ of diabetics in Eastern Libya had PDN, with age being a risk factor (Garoushi et al. 2019). In Saudi Arabia, 65.3\% of people have PDN (Halawa et al. 2010). In the Middle East, $53.7 \%$ of people have PDPN (Jambart et al. 2011). As a result, the prevalence of PDPN in this study is somewhat higher than in Belgium but lower than in Japan, Saudi Arabia, and the United Kingdom. The vascular risk factors were found in develops DPN in Type-2 DM (Pop-Busui et al. 2013, Andersen et al. 2018, Callaghan et al. 2018). Increasing age (Van Acker et al. 2009, Ziegler et al. 2009, Aleidan et al. 2020), higher HbA1c (Themistocleous et al. 2016, Algeffari 2018), and duration of DM are all identified risk factors (Van Acker et al. 2009, Aleidan et al. 2020). In chronic pain problems, gender differences are well established, and neuropathic pain intensity has previously been shown to be more severe in females (Sorge and Strath 2018, Shillo et al. 2019). Several research addressing genetic variations related to DPN and painful-DPN have been conducted as a result of recent breakthroughs in gene sequencing technology (Faber et al. 2012, Li et al. 2015, Meng et al. 2015a, Meng et al. 2015b, Blesneac et al. 2018). There has also been a lot of attention to the involvement of voltage-gated sodium channels in neuropathic pain recently. The Nav 1.7 sodium channel is well-known for its role in pain signaling, and mutations in its producing gene, SCN9A, cause unusual pain syndromes. Nav 1.7 mutations have also been found in idiopathic small fiber neuropathy studies (Faber et al. 2012) and painful DPN (Li et al. 2015). Furthermore, despite major disparities in a patient's clinical presentation, the neurological evaluation of PDPN and non-DPN patients is the same. PDPN appears to be associated with the female gender (Shillo et al. 2019), which is in line with our findings. Longterm glycaemic control is necessary to reduce the risk of PDN (Garoushi et al. 2019). A study indicated that $32.5 \%$ of people have had chronic pain every day in their distal lower limbs for longer than three months (Bouhassira et al. 2013), Although, in our study, the prevalence and duration of lower limb involvement are higher. In both type-1 and type-2 diabetes, the likelihood of developing distal polyneuropathies- including painful neuropathies- appears to be inversely related to glycaemic control and directly correlated with diabetes duration (Franklin et al. 1990, Harris et al. 1993, The Diabetes Control and Complications Trial Research Group 1993, Tesfaye et al. 2005, Smith and Singleton 2008) which is favorable to our research Controlling your glycemia can help you avoid having DPN (Callaghan et al. 2012) and stifle its progress 
(Pop-Busui et al. 2013). With rising pain severity, the burden of PDPN worsens (Gore et al. 2005, Alleman et al. 2015, Sadosky et al. 2015). The only strategy that has been found to reduce the risk of neuropathy in diabetic patients is intensive glucose management (Tesfaye and Selvarajah 2009, The Diabetes Control and Complications Trial Research Group 1993). Aside from having poor glycemic control, those who have had diabetes for a long time and are elderly are more likely to develop diabetic neuropathy (Tesfaye and Selvarajah 2009). Although the duration of diabetes is a well-known risk factor for chronic microvascular issues (Shin et al. 2009), rigorous blood glucose management has been found to reduce diabetic sequelae much more than conventional control for the same disease duration (The Advance Collaborative Group 2008). According to cohort studies, every $1 \%$ reduction in HbA1c levels is associated with a $37 \%$ reduction in the risk of microvascular complications (Clarke et al. 2004). Intensive glycemic control and lower levels of $\mathrm{HbA1c}$ are followed by a reduction in diabetic complications: in $\mathrm{HbA1c},<7 \%$ is associated with a $60 \%$ reduction in the incidence of peripheral neuropathy (Nathan 2013). As a result, HbA1c is an independent risk factor for DPN with PDPN and non-painful DPN.

\section{Conclusion}

The present findings of this study suggest that increasing $\mathrm{HbA1C}$ level is significantly associated with increased prevalence of DPN as well as PDPN and non-painful DPN and the risk increases markedly at $\mathrm{HbA1c}$ levels $\geq 8.8 \%$. The prevalence and risk of DPN, PDPN and non-painful DPN also increased with the advancement of age and longer duration of diabetes. Careful assessment of the risk factors of DPN, PDPN and non-painful DPN among diabetic patients, and control of HbA1c level and appropriate preventive measures and treatment are thus recommended. This must include effective communication between patients and physicians to maximize patient outcomes.

\section{References}

Abbott CA, Garrow AP, Carrington AL, Morris J, Van Ross ER and Boulton AJ (2005). Foot ulcer risk is lower in SouthAsian and African-Caribbean compared with European diabetic patients in the UK: the North-West diabetes foot care study. Diabetes Care, 28(8): 1869-1875.

Abbott CA, Malik RA, Van Ross ER, Kulkarni J and Boulton AJ (2011). Prevalence and characteristics of painful diabetic neuropathy in a large community-based diabetic population in the UK. Diabetes Care, 34(10): 2220-2224.

Advance Collaborative Group (2008). Intensive blood glucose control and vascular outcomes in patients with type 2 diabetes. New England Journal of Medicine, 358(24): 2560-2572.

Agrawal RP, Ola V, Bishnoi P, Gothwal S, Sirohi P and Agrawal R (2014). Prevalence of micro and macrovascular complications and their risk factors in type-2 diabetes mellitus. Journal of the Association of Physicians of India, 52: 45-48.

Aleidan FA, Ahmad BA, Alotaibi FA, Aleesa DH, Alhefdhi NA, Badri M, Gader AG (2020). Prevalence and Risk Factors for Diabetic Peripheral Neuropathy Among Saudi Hospitalized Diabetic Patients: A Nested Case-Control Study. International Journal of General Medicine, 13: 881.

Algeffari MA (2018). Painful diabetic peripheral neuropathy among Saudi diabetic patients is common but underrecognized: multicenter cross-sectional study at primary health care setting. Journal of family and Community Medicine, 25(1): 43-7.

Alleman CJ, Westerhout KY, Hensen M, Chambers C, Stoker M., Long S and Van Nooten FE (2015). Humanistic and economic burden of painful diabetic peripheral neuropathy in Europe: a review of the literature. Diabetes Research and Clinical Practice, 109(2): 215-225.

American Diabetes Association (2020). Standards of medical care in diabetes. Diabetes Care, 43(1): 135-151. 
American Diabetes Association (2021). Standards of medical care in diabetes. Diabetes Care, 44(1): 151-167.

Andersen ST, Witte DR, Dalsgaard EM, Andersen H, Nawroth P, Fleming T, Jensen TM, Finnerup NB, Jensen TS, Lauritzen T and Feldman EL (2018). Risk factors for incident diabetic polyneuropathy in a cohort with screendetected type 2 diabetes followed for 13 years: ADDITION-Denmark. Diabetes Care, 41(5): 1068-1075.

Ashok S, Ramu M, Deepa R and Mohan V (2002). Prevalence of neuropathy in type 2 diabetic patients attending a diabetes centre in South India. J Assoc. Physicians India, 50:546-50.

Aslam A, Singh J and Rajbhandari S (2014). Pathogenesis of painful diabetic neuropathy. Pain Research and Treatment; 412041

Attal N, Cruccu G, Baron RA, Haanpää M, Hansson P, Jensen TS and Nurmikko T (2010). "EFNS guidelines on the pharmacological treatment of neuropathic pain. European Journal of Neurology, 17(9): 1113-e88.

Blesneac I, Themistocleous AC, Fratter C, Conrad LJ, Ramirez JD, Cox JJ, Tesfaye S, Shillo PR, Rice AS, Tucker SJ and Bennett DL (2018). Rare Na V1. 7 variants associated with painful diabetic peripheral neuropathy. Pain, 159(3): 469-80.

Bloom DE, Cafiero E, Jané-Llopis E, Abrahams-Gessel S, Bloom LR, Fathima S, Feigl AB, Gaziano T, Hamandi A, Mowafi M and O'Farrell D (2012). The global economic burden of noncommunicable diseases (No. 8712). Program on the Global Demography of Aging.

BÖRü ÜT, Alp R, Sargin H, Koçer A, Sargin M, LüLECl A and Yayla A (2004). Prevalence of peripheral neuropathy in type 2 diabetic patients attending a diabetes center in Turkey. Endocrine Journal, 51(6): 563-567.

Bouhassira D, Letanoux M and Hartemann A (2013). Chronic pain with neuropathic characteristics in diabetic patients: a French cross-sectional study. PLoS One, 8(9): e74195.

Boulton AJ, Malik RA, Arezzo JC and Sosenko JM (2004). Diabetic somatic neuropathies. Diabetes Care, 27(6): 1458-1486.

Boulton AJ, Vinik Al, Arezzo JC, Bril V, Feldman EL, Freeman R, Malik RA, Maser RE, Sosenko JM and Ziegler D (2005). Diabetic neuropathies: a statement by the American Diabetes Association. Diabetes Care, 28(4): 956-962.

Boulton AJM, Gries FA and Jervell JA (1998). Guidelines for the diagnosis and outpatient management of diabetic peripheral neuropathy. Diabetic Medicine, 15(6): 508-514.

Bril V, England JD, Franklin GM, Backonja M, Cohen JA, Del Toro DR, Feldman EL, Iverson DJ, Perkins B, Russell JW and Zochodne DW (2011). Evidence-based guideline: treatment of painful diabetic neuropathy: report of the American Academy of Neurology, the American Association of Neuromuscular and Electrodiagnostic Medicine, and the American Academy of physical medicine and rehabilitation. Neurology, 76(20): 1758-65.

Brownlee M (2005). The pathobiology of diabetic complications: a unifying mechanism. Diabetes, 54(6): 1615-1625.

Cabezas-Cerrato J (1998). The prevalence of clinical diabetic polyneuropathy in Spain: a study in primary care and hospital clinic groups. Diabetologia, 41(11): 1263-1269.

Callaghan BC, Cheng HT, Stables CL, Smith AL and Feldman EL (2012). Diabetic neuropathy: clinical manifestations and current treatments. The Lancet Neurology, 11(6): 521-534.

Callaghan BC, Gao L, Li Y, Zhou X, Reynolds E, Banerjee M, Pop-Busui R, Feldman EL and Ji L (2018). Diabetes and obesity are the main metabolic drivers of peripheral neuropathy. Annals of Clinical and Translational Neurology, 5(4): 397-405.

Chang CM, Hsieh CJ, Huang JC and Huang IC (2012). Acute and chronic fluctuations in blood glucose levels can increase oxidative stress in type 2 diabetes mellitus. Acta Diabetologia, 49(1): 171-177.

Chaturvedi N, Abbott CA, Whalley A, Widdows P, Leggetter SY and Boulton AJ (2002). Risk of diabetes related amputation in South Asians vs. Europeans in the UK. Diabet Med., 19: 99-104. 
Clarke PM, Gray AM, Briggs A, Farmer AJ, Fenn P, Stevens RJ, Matthews DR, Stratton IM and Holman RR (2004). A model to estimate the lifetime health outcomes of patients with type 2 diabetes: the United Kingdom Prospective Diabetes Study (UKPDS) Outcomes Model (UKPDS No. 68). Diabetologia, 47(10): 1747-1759.

Darivemula S, Nagoor K, Patan SK, Reddy NB, Deepthi CS and Chittooru CS (2019). Prevalence and its associated determinants of Diabetic Peripheral Neuropathy (DPN) in individuals having type-2 diabetes mellitus in Rural South India. Indian Journal of Community Medicine, 44(2): 88.

Davies M, Brophy S, Williams R and Taylor A (2006). The prevalence, severity, and impact of painful diabetic peripheral neuropathy in type 2 diabetes. Diabetes Care, 29(7): 1518-1522.

Deli G, Bosnyak E, Pusch G, Komoly S and Feher G (2013). Diabetic neuropathies: diagnosis and management. Neuroendocrinology, 98(4): 267-280.

Deshpande MA, Holden RR and Gilron I (2006). The impact of therapy on quality of life and mood in neuropathic pain: what is the effect of pain reduction?. Anesthesia \& Analgesia, 102(5): 1473-1479.

Diabetes Control and Complications Trial Research Group (1993). The effect of intensive treatment of diabetes on the development and progression of long-term complications in insulin-dependent diabetes mellitus. New England Journal of Medicine, 329(14): 977-986.

Dworkin RH, Malone DC, Panarites CJ, Armstrong EP and Pham SV (2010). Impact of postherpetic neuralgia and painful diabetic peripheral neuropathy on health care costs. The Journal of Pain, 11(4): 360-368.

Dyck PJ, Kratz KM, Karnes JL, Litchy WJ, Klein R, Pach JM, Wilson DM, O'brien PC and Melton L (1993). The prevalence by staged severity of various types of diabetic neuropathy, retinopathy, and nephropathy in a population-based cohort: the Rochester Diabetic Neuropathy Study. Neurology, 43(4): 817-817.

Erbas T, Ertas M, Yucel A, Keskinaslan A and Senocak M (2011). Prevalence of peripheral neuropathy and painful peripheral neuropathy in Turkish diabetic patients. Journal of Clinical Neurophysiology, 28(1): 51-55.

Faber CG, Hoeijmakers JG, Ahn HS, Cheng X, Han C, Choi JS, Estacion M, Lauria G, Vanhoutte EK, Gerrits MM and Dib-Hajj S (2012). Gain of function Nav1. 7 mutations in idiopathic small fiber neuropathy. Annals of Neurology, 71(1): 26-39.

Feng Y, Schlosser FJ and Sumpio BE (2011). The Semmes Weinstein monofilament examination is a significant predictor of the risk of foot ulceration and amputation in patients with diabetes mellitus. Journal of Vascular Surgery, 53(1): 220-226.

Franklin GM, Kahn LB, Baxter J, Marshall JA and Hamman RF (1990). Sensory neuropathy in non-insulin-dependent diabetes mellitus: the San Luis Valley Diabetes Study. American Journal of Epidemiology, 131(4): 633-643.

Gallagher EJ, Leroith D and Karnieli E (2011). The metabolic syndrome from insulin resistance to obesity and diabetes. The Medical Clinics of North America, 95(5): 855-873.

Garoushi S, Johnson MI and Tashani OA (2019). A cross-sectional study to estimate the point prevalence of painful diabetic neuropathy in Eastern Libya. BMC Public Health, 19(1): 1-7.

Gionfriddo MR, McCoy RG and Lipska KJ (2014).The 2013 American Association of Clinical Endocrinologists' diabetes mellitus management recommendations: improvements needed. JAMA Internal Medicine, 174(2): 179-180.

Gore M, Brandenburg NA, Dukes E, Hoffman DL, Tai KS and Stacey B (2005). Pain severity in diabetic peripheral neuropathy is associated with patient functioning, symptom levels of anxiety and depression, and sleep. Journal of Pain and Symptom Management, 30(4): 374-385.

Gorst C, Kwok CS, Aslam S, Buchan I, Kontopantelis E, Myint PK and Mamas MA (2015). Long-term glycemic variability and risk of adverse outcomes: a systematic review and meta-analysis. Diabetes Care, 38(12): 2354-2369. 
Halawa MR, Karawagh A, Zeidan A, Mahmoud AE, Sakr M and Hegazy A (2010). Prevalence of painful diabetic peripheral neuropathy among patients suffering from diabetes mellitus in Saudi Arabia. Current Medical Research and Opinion, 26(2): 337-343.

Harris M, Eastman R and Cowie C (1993). Symptoms of sensory neuropathy in adults with NIDDM in the US population. Diabetes Care, 16(11): 1446-1452.

Hossain MA, Sarkar MK, Mahbub I and Islam SMS (2021). HbA1c variability has a strong relationship with peripheral sensory and motor neuropathy in type-2 diabetes mellitus. Journal of Bio-Science, 29(1): 93-100.

Hussain A, Rahim MA, Azad Khan AK, Ali SMK and Vaaler S (2005). Type 2 diabetes in rural and urban population: diverse prevalence and associated risk factors in Bangladesh. Diabetic Medicine, 22(7): 931-936

IDF Diabetes Atlas- 9th edition, 2019. https://www.diabetesatlas.org/en.

International Expert Committee (2009). International expert committee report on the role of the A1C assay in the diagnosis of diabetes. Diabetes Care, 32: 1327-34.

Jambart S, Ammache Z, Haddad F, Younes A, Hassoun A, Abdalla K, Selwan CA, Sunna N, Wajsbrot D and Youseif E (2011). Prevalence of painful diabetic peripheral neuropathy among patients with diabetes mellitus in the Middle East region. Journal of International Medical Research, 39(2): 366-377.

Jensen MP, Chodroff MJ and Dworkin RH (2007). The impact of neuropathic pain on health-related quality of life: review and implications. Neurology, 68(15): 1178-1182.

Kim SS, Won JC, Kwon HS, Kim CH, Lee JH, Park TS, Ko KS and Cha BY (2014). Prevalence and clinical implications of painful diabetic peripheral neuropathy in type 2 diabetes: results from a nationwide hospital-based study of diabetic neuropathy in Korea. Diabetes Research and Clinical Practice, 103(3): 522-529.

King GL and Das-Evcimen N (2010). Role of protein kinase C in diabetic complications. Expert Review of Endocrinology and Metabolism, 5(1): 77-88.

Knuiman MW, Welborn TA, McCann VJ, Stanton KG and Constable IJ (1986). Prevalence of diabetic complications in relation to risk factors. Diabetes, 35: 1332-39.

Kumar HKVS, Kota SK, Basile A and Modi KD (2012). Profile of microvascular disease in type 2 diabetes in a tertiary health care hospital in India. Ann Med Health Sci. Res., 2(2): 103-108.

Lauria G and Lombardi R (2012). Small fiber neuropathy: is skin biopsy the holy grail?. Current Diabetes Reports, 12(4): 384-392.

Lee WJ, Jang S, Lee SH and Lee HS (2016). Correlation between the severity of diabetic peripheral polyneuropathy and glycosylated hemoglobin levels: a quantitative study. Annals of Rehabilitation Medicine, 40(2): 263.

Li QS, Cheng P, Favis R, Wickenden A, Romano G and Wang H (2015). SCN9A variants may be implicated in neuropathic pain associated with diabetic peripheral neuropathy and pain severity. The Clinical Journal of Pain, 31(11): 976.

Meng W, Deshmukh HA, Donnelly LA, markers for Micro S, Torrance N, Colhoun HM, Palmer CN and Smith BH (2015a). A genome-wide association study provides evidence of sex-specific involvement of Chr1p35. 1 (ZSCAN20TLR12P) and Chr8p23. 1 (HMGB1P46) with diabetic neuropathic pain. European BioMedicine, 2(10): 1386-1393.

Meng W, Deshmukh HA, Van Zuydam NR, Liu Y, Donnelly LA and Zhou K (2015b). A genome-wide association study suggests an association of C hr8p21. 3 (GFRA2) with diabetic neuropathic pain. European J. Pain, 19(3): 392-399.

Mørkrid K, Ali L and Hussain A (2010). Risk factors and prevalence of diabetic peripheral neuropathy: a study of type 2 diabetic outpatients in Bangladesh. International Journal of Diabetes in Developing Countries, 30(1): 11-17 
Narres M, Kvitkina T, Claessen H, Droste S, Schuster B, Morbach S, Rümenapf G, Van Acker K and Icks A (2017). Incidence of lower extremity amputations in the diabetic compared with the non-diabetic population: a systematic review. PLoS One, 12(8): e0182081.

Nathan DM (2013). The Diabetes Control and Complications Trial/Epidemiology of Diabetes Interventions and Complications Study at 30 Years: Overview. Diabetes Care, 37: 9-16.

National Institute for Health and Care Excellence (2013). NICE clinical guideline 173. Neuropathic pain- pharmacological management. The pharmacological management of neuropathic pain in adults in nonspeicalist settings. http://guidance.nice.org.uk/CG173.

Obrosova IG (2009). Diabetic painful and insensate neuropathy: pathogenesis and potential treatments. Neurotherapeutics, 6(4): 638-647.

O'Connor AB (2009). Neuropathic pain: quality-of-life impact, costs and cost effectiveness of therapy. Pharmaco Economics, 27(2): 95-113.

Pop-Busui R, Boulton AJ, Feldman EL, Bril V, Freeman R, Malik RA, Sosenko JM and Ziegler D (2017). Diabetic neuropathy: a position statement by the American Diabetes Association. Diabetes Care, 40(1): 136-154.

Pop-Busui R, Lu J, Brooks MM, Albert S, Althouse AD, Escobedo J, Green J, Palumbo P, Perkins BA, Whitehouse F and Jones TL (2013). Impact of glycemic control strategies on the progression of diabetic peripheral neuropathy in the Bypass Angioplasty Revascularization Investigation 2 Diabetes (BARI 2D) Cohort. Diabetes Care, 36(10): 3208-3215.

Punjot P, Bishnoi R, Kant R and Sharma SK (2021). Factors associated with peripheral neuropathy among patients with type 2 diabetes mellitus: A cross-sectional study. Journal of Cardio-Diabetes and Metabolic Disorders, 1(1): 25.

Ramachandran A, Snehalatha C, Satyavani K, Latha E, Sasikala R and Vijay V (1999). Prevalence of vascular complications and their risk factors in type 2 diabetes. The Journal of the Association of Physicians of India, 47(12): 1152-1156.

Raputova J, Srotova I, VIckova E, Sommer C, Üçeyler N, Birklein F, Rittner HL, Rebhorn C, Adamova B, Kovalova I and Nekvapilova EK (2017). Sensors phenotype and risk factors for painful diabetic neuropathy: A cross-sectional observational study. Pain, 158(12): 2340-53.

Sabanayagam C, Liew G, Tai ES, Shankar A, Lim SC, Subramaniam T and Wong TY (2009). Relationship between glycated haemoglobin and microvascular complications: is there a natural cut-off point for the diagnosis of diabetes? Diabetologia, 52(7):1279.

Sadosky A, Mardekian J, Parsons B, Hopps M, Bienen EJ and Markman J (2015). Healthcare utilization and costs in diabetes relative to the clinical spectrum of painful diabetic peripheral neuropathy. Journal of Diabetes and its Complications, 29(2): 212-217.

Sadosky A, McDermott AM, Brandenburg NA and Strauss M. (2008). A review of the epidemiology of painful diabetic peripheral neuropathy, postherpetic neuralgia, and less commonly studied neuropathic pain conditions. Pain Practice, 8(1): 45-56.

Schisano B, Tripathi G, McGee K., McTernan PG and Ceriello A (2011). Glucose oscillations, more than constant high glucose, induce p53 activation and a metabolic memory in human endothelial cells. Diabetologia, 54(5): 1219-1226.

Shillo P, Sloan G, Greig M, Hunt L, Selvarajah D, Elliott J, Gandhi R, Wilkinson ID and Tesfaye S (2019). Painful and painless diabetic neuropathies: what is the difference? Current Diabetes Reports, 19(6): 32

Shin YS, Kim MO, Kim CH and Nam MS (2009). Relation of nerve conduction study and physical parametersin diabetic polyneuropathy. Journal of Korean Academy of Rehabilitation Medicine, 33(1): 112-117.

Smith AG and Singleton JR (2008). Impaired glucose tolerance and neuropathy. The Neurologist, 14(1): 23-29.

Sorge RE and Strath LJ (2018). Sex differences in pain responses. Current Opinion in Physiology, 6: 75-81. 
Suljic E, Kulasin I and Alibegovic V (2013). Assessment of diabetic polyneuropathy in inpatient care: fasting blood glucose, HbA1c, electroneuromyography and diabetes risk factors. Acta Inform. Med., 21(2): 123-26.

Taylor-Stokes G, Pike J, Sadosky A, Chandran A and Toelle T (2011). Association of patient-rated severity with other outcomes in patients with painful diabetic peripheral neuropathy. Diabetes, Metabolic Syndrome and Obesity: Targets and Therapy, 4: 401.

Tesfaye S (2009). Advances in the management of diabetic peripheral neuropathy. Curr Opin Support Palliat Care, 3(2): 136-143.

Tesfaye S and Selvarajah D (2009). The Eurodiab study: what has this taught us about diabetic peripheral neuropathy? Current Diabetes Reports, 9(6): 432-434.

Tesfaye S, Chaturvedi N, Eaton SE, Ward JD, Manes C, Ionescu-Tirgoviste C, Witte DR and Fuller JH (2005). Vascular risk factors and diabetic neuropathy. New England Journal of Medicine, 352(4): 341-350.

Themistocleous AC, Ramirez JD, Shillo PR, Lees JG, Selvarajah D, Orengo C, Tesfaye S, Rice AS and Bennett D (2016). The Pain in Neuropathy Study (PiNS): a cross-sectional observational study determining the somatosensory phenotype of painful and painless diabetic neuropathy. Pain, 157(5): 1132.

Toth C, Rong LL, Yang C, Martinez J, Song F, Ramij N, Brussee V, Liu W, Durand J, Nguyen MD and Schmidt AM (2008). Receptor for advanced glycation end products (RAGEs) and experimental diabetic neuropathy. Diabetes, 57(4): 1002-1017.

Tsuji M, Yasuda T, Kaneto H, Matsuoka TA, Hirose T, Kawamori R, Iseki M, Shimomura I and Shibata M (2013). Painful diabetic neuropathy in Japanese diabetic patients is common but under recognized. Pain Research and Treatment, ID-318352, http://dx.doi.org/10.1155/2013/318352.

Van Acker K, Bouhassira D, De Bacquer D, Weiss S, Matthys K, Raemen H, Mathieu C and Colin IM (2009). Prevalence and impact on quality of life of peripheral neuropathy with or without neuropathic pain in type 1 and type 2 diabetic patients attending hospital outpatients clinics. Diabetes and Metabolism, 35(3): 206-213.

Veves A, Backonja M and Malik RA (2008). Painful diabetic neuropathy: epidemiology, natural history, early diagnosis, and treatment options. Pain Medicine, 9(6): 660-674.

Vinik Al and Ziegler D (2007). Diabetic cardiovascular autonomic neuropathy. Circulation, 115(3): 387-397.

Vinik Al, Park TS, Stansberry KB and Pittenger GL (2000). Diabetic neuropathies. Diabetologia, 43: 957-73.

Young MJ, Boulton AJ, MacLeod AF, Williams DR and Sonksen PH (1993). A multicentre study of the prevalence of diabetic peripheral neuropathy in the United Kingdom hospital clinic population. Diabetologia, 36: 150-54.

Ziegler D, Rathmann W, Dickhaus T, Meisinger C and Mielck A (2009). Neuropathic pain in diabetes, prediabetes and normal glucose tolerance: the MONICA/KORA Augsburg Surveys S2 and S3. Pain Medicine, 10(2): 393-400.

Zigmond AS and Snaith RP (1983). The hospital anxiety and depression scale. Acta Psychiatrica Scandinavica, 67(6): 361-370.

Zoungas S, Chalmers J, Ninomiya T, Li Q, Cooper ME, Colagiuri S, Fulcher G, Galan BE de Harrap S, Hamer P, MacMahon S, Marre M, Poulter N, Patel A and Neal B, Woodward M and Heller S (2012). Association of HbA1C levels with vascular complications and death in patients with type 2 diabetes: evidence of glycaemic thresholds. Diabetologia, 55(3): 636-643. 